\title{
A comprehensive radiography of intoxication as persuasive action
}

\author{
John H. Gasderell \\ University of Oklahoma, 660 Parrington Oval, Norman, OK 73019, United States \\ E-mail address: jhgasderell@yahoo.com
}

\begin{abstract}
The research aims a) to make visible joints of informational intoxication as persuasive communication action and $b$ ) to differentiate informational intoxication from disinformation and manipulation. It stresses that the action of intoxication consists in an assembly of informative measures aimed at influencing a target by introducing into its informational flow some information determining the vitiation of the functional decisions through influence. The main ontological elements of the intoxication process are agent of intoxication, target of intoxication, intoxication message, intoxication channel and intoxication situation. The most difficult to realize in informational intoxication is to install, to institute the intoxication situation that situation in which the agent creates attracts the target into deliberately and consciously participating to its own intoxication.
\end{abstract}

Keywords: intoxication; persuasive communication; intoxication situation

\section{INTRODUCTION}

The lexeme "intoxication" does not exceed the verbal comprehension with an average quality speaker of Romanian language. It means the action to introduce toxins into the functional circuits of an organism. The neologism of French origin (intoxication) is explained by "Petit Robert" (Robert, 1999) as meaning an "insidious action on the spirits, tending to accredit certain opinions, to demoralise, to confuse". According to Vladimir Volkoff (Volkoff, 2004), intoxication as persuasive technique is of military origin. The main theorist of intoxication is Pierre Nord. His real name is André Brouillard, is a former colonel in the French army, Nord publishes in 1971 the study "L'intoxication", imposing a new informational "operation" through the clarifications made.

\section{ONTOLOGICAL ELEMENTS OF INTOXICATION}

Considered "technique" by V. Volkoff and "operation" by P. Nord, intoxication is an assembly of operations, meaning an action. When action of intoxication is vested with an amplitude of forces, means and effects, it becomes operation. The basic operation presiding over intoxication is the lie. According to the situation, it is supported by seduction, fiction as well as myth. The action of intoxication consists in an assembly of informative measures aimed at influencing a target by introducing into its informational flow some information determining 
the vitiation of the functional decisions through influence (Colhon, 2013; Borowski, 2013; Borowski, 2014).

The main actor of the intoxication project is the agent of intoxication. The model of this type of agent convergently attracts features such as: credibility in the environment, convictivepersuasive capability, access to decision-makers or occupation of a decisional position, authority, legitimacy in manifesting attitudes, prestige (Vlăduţescu, 2013; Gîfu, 2014; Vlăduţescu, 2014). They must be confident of their own forces and self-control, must be intelligent and adaptable. They shall manifest these qualities to enter into the adverse device and place towards the top of the hierarchy, either as position, or as influence. They shall be in the centre of the gear which shall perform the message by beans of which the chosen target is to be intoxicated. They shall create the illusion of credibility and shall classify the intoxicating speech on the logical path of derivation from an authentic reality (Siminică \& Traistaru, 2013; Strechie, 2014; Traistaru \& Avram, 2014).

The targets of the action of intoxication, states H.-P. Cathala (1986), would be limited: decision-makers, majors states, governments, secret services. The limited features of the set of intoxication targets correspond to a low range of influence: intoxication occurs at the level of the bodies with functional tasks.

V. Volkoff makes of the extension of the concerned targets the basic criterion for differentiating the intoxication of disinformation. For him, "the difference between intoxication and disinformation is that the first concerns a general staff, a small group of decision-makers, possibly a commander in chief, whereas disinformation is addressed to the public opinion" (Volkoff, 2004). According to him, it would be self understood that intoxication is not reserved to the military field. A political party, a bank, a manufacturer, a newspaper can profit by the intoxication, however the purpose shall always be to determine the people, and not collectives, to act in their own disservice. One seeks just the effect of intoxication and how policymakers shall intoxicate those around them is not turned into an ideal. Once intoxicated, the policymaker shall take intoxicated decisions, meaning in the sense of the "prospectus" of toxins administered.

Therefore, the action of intoxication dissipates its forces and the largest part of energies on injecting the informational toxins. The opinion of H.-P. Cathala, that "leadership factors can be intoxicated, but the population remains distrustful" (Cathala H.-P., 1991, p. 248) is judicious only in the initial terms of the action of intoxication. Ultimately, the effects of contagion shall be seen among the masses. Intoxicating the decision-makers is contagious. It emerges that intoxication has a limited range of targets, which however propagates the intoxicating influence into social groups. Like any action, the action of intoxication is performed in a planned and organised manner, in order to cover a need, for the achievement of a purpose, in performing certain objectives.

The development of the intoxicating message, allocation of intoxicating forces, fixation of means and methods of dissemination are at the centre of the plan. Organising and planning the intoxication must take into account a period of preparation and an interval of performance, and within the performance, the achievement of two effects:

- an immediate one of surprise, triggering emotional energies, which would be capitalised by the operation of seduction;

- another one of deceit mediated by the intoxicating message, which would determine the allocation of cogitative energies to assimilate the insidious toxin, an effect obtained though lying. 
The intoxicating message focuses on a basic, real, authentic, veridical, familiar, notorious fact; operations of distortion are applied to it and elements of falseness are added to it. In reality, the message carries with itself a coverage fact and the toxins. Besides the information in relation to the basic fact and toxic information, the message shall also contain:

- information to cover the informational mandate of the agent of intoxication, consisting in data and evocation of facts which would confirm and cover the performance of the agent of intoxication, allowing them to exculpate themselves in relation to a potential accusation of deception and lie (Kot, Grabara \& Kolcun, 2014; Bajdor \& Grabara, 2014);

- information of accreditation (that exact, validatable and verifiable which the agent transmits to the target from the beginning);

- toxins - related information and primed by the information of accreditation; when the information of accreditation is not contested by its incompletion and its temporal shift can be added to toxins, as a product of toxic pre-synthesising;

- recycling-recovery information: information inserted to preventively ensure the withdrawal in case of failure; exploiting this information, the agent shall be a target that would accuse them of lying or of deceiving to accept it is a matter of an error on their part, and not a condemnable intention; the "error" would keep the good faith and prestige;

- explanatory information: information which the agent shall use to persuade the decision-maker they are aware of the intoxication that, in fact, their gesture is legitimate and justified.

The preferred channel to implement the intoxication is the media. The specificity of intoxication is its inferential articulation. In fact, the target produces the intoxication itself. True information and false information is made available to it. From this conglomerate, the target builds a premise and draw an intoxicating conclusion and subsequently promotes it. Pierre Nord's hypothesis may be called intoxication as synthesis. The French specialist shows that the target is provided with partial information which it synthesises; when the intoxication has been well driven, the synthesis produced shall be the idea which was designed to be induced and inserted into the mind (Nord, 1971, pp. 12-18). The intoxication mechanism consists in inferentially processing a complex message. The situation of intoxication which the agent creates attracts the target into deliberately and consciously participating to its own intoxication. Concurrently, the distribution of the intoxicating opinion is also ensured (Gîfu \& Teodorescu, 2014; Nowicka-Skowron \& Radu, 2014).

According to V. Volkoff (Volkoff, 2004), a second criterion to differentiate between intoxication and disinformation, after the synthesis, is that the latter cannot be imagined without sounding boardes. In other words, intoxication can survive without sounding boardes, it can be limited to direct influence, without necessarily needing a secondary transfer of influence.

A third criterion to delimit the disinformation intoxication is given by H.-P. Cathala. He gives the intoxication a short time of performance and obtaining "a rapid if not an immediate effect" (Cathala, 1986). Taking into account that intoxication is addressed to a limited number of targets, the effects can occurs in a short time.

Historically, intoxication has been successfully used in World War II. To this effect, the intoxication that preceded the landing in Sicily is noteworthy. To be mentioned that the British, as Volkoff (Volkoff, 2004) states, "have taken intoxication to a high degree of perfection", creating an office called the Doublecross, deceit, hoax), specialised in camouflaging the squadrons from false airplanes and regiments from false tanks, in order to deceive the enemy on the landing sites. 
By taking into account the limited addressability (first of all, decision-makers) and that it is based on an inferential logic of propagating the lie through seduction, it is shown that, above all, the decision-makers must be protected and protect against intoxication (Dima \& Vlăduţescu, 2012; Vlăduţescu \& Ciupercă, 2013). They should be advised not to let themselves be seduced by the information imposed by taking certain decisions in a short time.

\section{DETECTING THE INTOXICATION}

Detecting the intoxication-type aggressions may be done by analysing the crossed media speeches in relation to the issuing source. As symptoms of intoxication, one must take into account the clarity of the speech and irreproachability of reasons by means of which information is processed, information that is excessively provided and reinforced in terms of legitimacy and credibility. Intoxication is very dangerous as long as it remains non-decoded. In order to avoid intoxication, it must be identified, and identification is the target of an analysis which would guide itself according to the some objectives:

- deciphering elements of a persuasive action: lie, seduction, fiction, myth;

- notifying a discursive plethora;

- clarifying a persuasive message;

- detecting the subjacent ideology;

- identifying the intoxication situation: visibility of the persuaded (target-group), of the persuader, and of the intoxication message;

- emphasising the intoxication technology;

- highlighting the systematic and organised feature of persuasion;

- detecting the elements of the intoxication action, operation, campaign;

- distinguishing between intoxication, disinformation and manipulation.

The identification of intoxication, as a basis for neutralisation and counteraction, shall be done by operations consisting of:

- discovering the intoxication message;

- establishing the de facto inaccuracies concerning the elements of reality in a situation of congruity with those which the speech of adversary intoxication is based on (putting the intoxication in opposition to the evidence of facts);

- highlighting the vulnerabilities in the idea of gradually dismantling the advanced negative theses;

- observing the operational errors (Powell, 2014);

- detecting the argumentation mistakes due to the lack of factual support (proving the factoid feature of some events).

The counter-intoxication response must start from the observations in relation to the intoxication message and intoxication discourse. It must be organised based on a plan and must be articulated particularly for:

- stopping the information circulated by the intoxication by highlighting its incoherence and falseness and by disseminating real information, reliable, authentic, which would neutralize the intoxication information (Teodorescu, 2014);

- clarifying the adverse intoxication discourse by revealing its true intentions;

- debilitating the entire adverse approach as intoxication;

- devaluating the course of the adverse intoxication. 


\section{CONCLUSION}

The specificity of intoxication is its inferential articulation. In fact, the target produces the intoxication itself. True information and false information is made available to it. From this conglomerate, the target constructs a premise and draws an intoxicating conclusion and subsequently promotes it. The intoxication mechanism consists in inferentially processing a complex message. The situation of intoxication which the agent creates attracts the target into deliberately and consciously participating to its own intoxication. Concurrently, the distribution of the intoxicating opinion is also ensured.

\section{References}

[1] Vladimir Volkoff (Ed.). (2004). La désinformation: arme de guerre. l'Âge d'homme.

[2] P. Nord (1971). L'intoxication, arme absolue de la guerre subversive. Fayard.

[3] Max G. Craig, Journal of Studies in Social Sciences 8(1) (2014).

[4] Andrzej Borowski, International Letters of Social and Humanistic Sciences 14 (2014) 7-17.

[5] Cathala H. P. (1986). Le Temps de la desinformation. Stock.

[6] M. Dynel, Poznań Studies in Contemporary Linguistics PSiCL 47 (2011) 283.

[7] Jason L. Powell, International Letters of Social and Humanistic Sciences 16(2) (2014) 177-183.

[8] Andrzej Borowski, International Letters of Social and Humanistic Sciences 4 (2013) 70-74.

[9] M. Nowicka-Skowron, S. M. Radu (2014). The information and company's innovativecreative activity under the current conditions of the market economy. Communication Neutrosophic Routes.

[10] Ioan Constantin Dima, Ştefan Vlăduţescu (2012). Persuasion elements used in logistical negotiation: Persuasive logistical negotiation. Saarbrucken: LAP Lambert Academic Publishing.

[11] Andrzej Borowski, International Letters of Social and Humanistic Sciences 14 (2014) $33-41$.

[12] C. K. Atkin (1988). Mass communication effects on drinking and driving. In Surgeon General's Workshop on Drunk Driving (pp. 15-34).

[13] M. Siegrist, H. Gutscher, C. Keller (2010). Trust and confidence in crisis communication: three case studies. Trust in Risk Management: Uncertainty and Scepticism in the Public Mind.

[14] A. Borowski, International Letters of Social and Humanistic Sciences 11 (2014) 1-168.

[15] A. Traistaru, M. Avram, International Letters of Social and Humanistic Sciences 13 (2014) 79-88.

[16] Ş. Vlăduţescu, E. M. Ciupercă (2013). Next Flood Level of Communication: Social Networks. Aachen: Shaker Verlag. 
[17] Janusz Grabara, Michal Kolcun, Sebastian Kot, International Journal of Education and Research 2(2) (2014).

[18] Marian Siminică, Aurelia Traistaru, International Journal of Education and Research 1(12) 2013.

[19] Sebastian Kot, Janusz Grabara, Michal. Kolcun, International Letters of Social and Humanistic Sciences 15 (2014) 1-6.

[20] Alina Tenescu, Mirela Teodorescu, Communications in Applied Sciences 2(1) (2014).

[21] Ștefan Vlăduțescu (2013). Principle of the Irrepressible Emergence of the Message. Jokull.

[22] Colhon M. (2013). Automatic Lexical Alignment between Syntactically Weak Related Languages. Application for English and Romanian. In Computational Collective Intelligence. Technologies and Applications (pp. 266-275). Springer Berlin Heidelberg.

[23] Daniela Gîfu, Mirela Teodorescu, International Letters of Social and Humanistic Sciences 18 (2014) 34-38.

[24] Ştefan Vlăduţescu (2013). What Kind of Communication Is Philosophy. Jokull.

[25] Janusz Grabara, Mariana Man, Michal Kolcun, International Letters of Social and Humanistic Sciences 15 (2014) 138-147.

[26] Daniela Gîfu, Dan Ionescu, Mirela Teodorescu, International Letters of Social and Humanistic Sciences 17 (2014) 61-69.

[27] Jason L. Powell, International Letters of Social and Humanistic Sciences 7 (2014) 22-30.

[28] Daniela Gîfu, Mirela Teodorescu, International Letters of Social and Humanistic Sciences 17 (2014) 119-127.

[29] Andrezj Borowski, International Letters of Social and Humanistic Sciences 2 (2014) 110-121.

[30] Ştefan Vlăduţescu, International Letters of Social and Humanistic Sciences 10(2) (2014) 100-106.

[31] Daniela Gîfu (2014). Humor in the Religious Discourse: between Paradoxism and Neutrosophy. Communication Neutrosophic Routes.

[32] Paula Bajdor, Iwona Grabara, Journal of Studies in Social Sciences 7(2) (2014).

[33] Mădălina Strechie (2014). Communication as the Main Source of Neutrality in Ancient Rome. Communication Neutrosophic Routes.

[34] S. M. Radu, International Letters of Social and Humanistic Sciences 16 (2014) 184-193.

[35] Andrezj Borowski, International Letters of Social and Humanistic Sciences 3 (2013) 69-74.

[36] Bianca Teodorescu (2014). A neutrosophic mirror between communication and information. Communication Neutrosophic Routes.

[37] Mădălina Giorgiana Mangra, Elena Antoanela Cotoc, Aurelia Traistaru, Journal of Studies in Social Sciences 6(1) (2013). 
[38] Ştefan Vlăduțescu, International Letters of Social and Humanistic Sciences 18 (2014) 80-89.

[39] Daniela Gîfu, Mirela Teodorescu, International Letters of Social and Humanistic Sciences 18 (2014) 48-57.

[40] Jason L. Powell, International Letters of Social and Humanistic Sciences 17(1) (2014) $1-60$.

[41] Ioan Constantin Dima, Mariana Man (2014). Information and Computer Engineering in neutrosophic managerial decision. Communication Neutrosophic Routes.

[42] A. Traistaru (2013). Consolidation of the green marketing profile in current austerity period. Jokull.

[43] Janusz Grabara, Vladimir Modrak, Ioan Constantin Dima, International Letters of Social and Humanistic Sciences 15 (2014) 148-156.

[44] Petre Bosun, Alina Tenescu, Ioan Constantin Dima, International Letters of Social and Humanistic Sciences 16 (2014). 75-85.

[45] Jason L. Powell, International Letters of Social and Humanistic Sciences 16(2) (2014) 108-121. 